\title{
Baseline D-Dimer Levels as a Risk Assessment Biomarker for Recurrent Stroke in Patients with Combined Atrial Fibrillation and Atherosclerosis
}

\author{
Kang-Ho Choi ${ }^{1, *}$, Woo-Keun Seo ${ }^{2, *}{ }^{\mathbb{C}}$, Man-Seok Park ${ }^{1}$, Joon-Tae Kim ${ }^{1}$, Jong-Won Chung ${ }^{2}$, \\ Oh Young Bang ${ }^{2}$, Geong-Moon Kim ${ }^{2}$, Tae-Jin Song ${ }^{3}$, Bum Joon Kim ${ }^{4}$, Sung Hyuk Heo ${ }^{4}$, \\ Jin-Man Jung ${ }^{5}$, Kyungmi Oh ${ }^{6}{ }^{\circ}$, Chi Kyung Kim ${ }^{6}$, Sungwook Yu ${ }^{7}$, Kwang Yeol Park ${ }^{8}$, \\ Jeong-Min Kim ${ }^{8}$, Jong-Ho Park ${ }^{9}$, Jay Chol Choi ${ }^{10}$, Yang-Ha Hwang ${ }^{11}$ and Yong-Jae Kim ${ }^{12}$
}

1 Department of Neurology, Chonnam National University School of Medicine and Hospital, Gwangju 61469, Korea; mspark@chonnam.ac.kr (M.-S.P.); alldelight2@chonnam.ac.kr (J.-T.K.)

2 Department of Neurology, Samsung Medical Center, Sungkyunkwan University School of Medicine, Seoul 06351, Korea; neurocjw@gmail.com (J.-W.C.); ohyoung.bang@samsung.com (O.Y.B.); gyeongmoon.kim@samsung.com (G.-M.K.)

3 Department of Neurology, Ewha Womans University, Seoul 03760, Korea; knstar@hanmail.net

4 Department of Neurology, Kyung Hee University College of Medicine, Seoul 02447, Korea; medicj80@daum.net (B.J.K.); shheo73@hanmail.net (S.H.H.)

5 Department of Neurology, Korea University Ansan Hospital, Korea University College of Medicine, Kyungki-Do 15355, Korea; sodium75@hanmail.net

6 Department of Neurology, Korea University Guro Hospital, Korea University College of Medicine, Seoul 08308, Korea; okyungmi@korea.ac.kr (K.O.); ckkim7@gmail.com; (C.K.K.)

7 Department of Neurology, Korea University Hospital, Korea University College of Medicine, Seoul 02841, Korea; song4yu@korea.ac.kr

8 Department of Neurology, Chung-Ang University College of Medicine, Seoul 06974, Korea; kwangyeol.park@gmail.com (K.Y.P.); bellokim@cau.ac.kr (J.-M.K.)

9 Department of Neurology, Myongji Hospital, Hanyang University College of Medicine, Goyang 10475, Korea; neurotector.jhp@gmail.com

10 Department of Neurology, Jeju National University, Jeju 63241, Korea; jaychoi@jejunu.ac.kr

11 Department of Neurology, Cerebrovascular Center Kyungpook National University School of Medicine and Hospital, Daegu 41944, Korea; yangha73@gmail.com

12 Department of Neurology, Eunpyeong St. Mary's Hospital, The Catholic University of Korea, Seoul 03312, Korea; brain930@ewha.ac.kr

* Correspondence: ckhchoikang@hanmail.net (K.-H.C.); mcastenosis@gmail.com (W.-K.S.);

Tel.: +82-62-220-6137 (K.-H.C.); +82-2-3410-0799 (W.-K.S.);

Fax: +82-62-228-3461 (K.H.-C.); +82-2-3410-0630 (W.-K.S.)

Received: 9 August 2019; Accepted: 10 September 2019; Published: 13 September 2019

Abstract: Background: We investigated the effect of D-dimer levels and efficacy of different antithrombotic therapies according to the baseline D-dimer levels on recurrent stroke in patients with atrial fibrillation (AF)-related stroke and atherosclerosis. Methods: We enrolled 1441 patients with AF-related stroke and atherosclerosis in this nationwide multicenter study. The primary outcome measure was the occurrence of recurrent ischemic stroke over a 3-year period. Results: High D-dimer levels ( $\geq 2 \mu \mathrm{g} / \mathrm{mL}$ ) were significantly associated with higher risk of recurrent ischemic stroke (adjusted hazard ratio $(\mathrm{HR}), 1.80 ; 95 \%$ confidence interval $(\mathrm{CI}), 1.13-2.84 ; p=0.012)$. The risk of recurrent stroke was similar between the anticoagulant and the antiplatelet groups in all subjects (adjusted $\mathrm{HR}, 0.78 ; 95 \% \mathrm{CI}, 0.46-1.32 ; p=0.369)$. However, in patients with high D-dimer levels $(\geq 2 \mu \mathrm{g} / \mathrm{mL})$, risk of recurrent stroke was significantly lower in the anticoagulant group than in the antiplatelet group (adjusted HR, 0.40; 95\% CI, 0.18-0.87; $p=0.022$ ). Conclusion: Our findings suggested that baseline D-dimer levels could be used as a risk assessment biomarker of recurrent stroke in patients 
with AF-related stroke and atherosclerosis. High D-dimer levels would facilitate the identification of patients who are more likely to benefit from anticoagulants to ensure secondary prevention of stroke.

Keywords: atrial fibrillation; d-dimer; outcome; ischemic stroke; antithrombotics

\section{Introduction}

Stroke is a heterogeneous disease with multiple risk factors and causes [1]. Secondary prevention of recurrent ischemic stroke targets the mechanisms responsible for the stroke index [2]. Several studies have recommended the use of antiplatelet agents instead of oral anticoagulants (OACs) to address atherosclerosis-associated non-cardioembolic stroke, but OACs for cardioembolic stroke during secondary prevention [3]. However, several patients either demonstrated both cardioembolic and non-cardioembolic etiologies or are at a high risk of concomitant cardio- and peripheral-atherosclerotic diseases and recurrent cardioembolic stroke [4]. Although guidelines recommend OACs for patients with atrial fibrillation (AF) and stroke, including those with atherosclerotic diseases, there is insufficient evidence to successfully identify which antithrombotic therapies are more effective for secondary prevention of stroke in patients with AF and atherosclerosis [3]. Furthermore, a tailored antithrombotic strategy based on a risk assessment biomarker for recurrent stroke in these patients has not yet been established [1].

Previous reports suggest that plasma D-dimer levels-a thrombin generation and fibrin turnover biomarker-may be a clinically useful risk assessment biomarker for stroke in patients with AF [5]. Higher baseline D-dimer levels were associated with increased frequencies of stroke in AF patients [6,7]. The efficacy of anticoagulants for stroke prevention in AF patients could be related to the suppression of elevated D-dimer levels. Similarly, the superior ability of non-vitamin K antagonist OACs (NOACs) to further reduce elevated D-dimer levels compared to warfarin might be attributed to the relatively higher efficacy of NOACs $[7,8]$. However, there are no reports that have examined the effect of D-dimer levels or proper antithrombotic strategies according to baseline D-dimer levels for secondary prevention of stroke in patients with $\mathrm{AF}$ and atherosclerosis.

Therefore, we investigated the impact of D-dimer levels and the efficacy of different antithrombotic therapies according to the baseline D-dimer levels on the prevalence of recurrent stroke in a nationwide population of patients with AF-related stroke and atherosclerotic diseases.

\section{Materials and Methods}

\subsection{Subjects}

To conduct this retrospective study, we used data from a prospective, nationwide, multicenter registry the Korean Atrial Fibrillation Evaluation Registry in Ischemic Stroke Patients (K-ATTENTION) - a database of consecutive acute ischemic stroke (AIS) patients with AF who were admitted to 11 medical centers in South Korea between January 2013 and December 2015. Among the 3213 patients registered in the database, we included those who met the following conditions: (1) presence of atherosclerotic vascular diseases (ischemic stroke presumed arterial origin or atherosclerosis in the carotid, intracranial, coronary, or peripheral arteries), and (2) patients taking antithrombotic agents at discharge. Patients were excluded if they (1) had incomplete data for D-dimer levels, (2) had incomplete data for clinical outcomes over a 3-year period, and (3) were diagnosed with AF after discharge.

The impact of D-dimer levels on recurrent stroke was investigated by categorizing the study subjects into groups based on prespecified baseline D-dimer levels $(<0.5 \mu \mathrm{g} / \mathrm{mL}$ vs. $\geq 0.5 \mu \mathrm{g} / \mathrm{mL}$; $<1 \mu \mathrm{g} / \mathrm{mL}$ vs. $\geq 1 \mu \mathrm{g} / \mathrm{mL} ;<2 \mu \mathrm{g} / \mathrm{mL}$ vs. $\geq 2 \mu \mathrm{g} / \mathrm{mL} ;<3 \mu \mathrm{g} / \mathrm{mL}$ vs. $\geq 3 \mu \mathrm{g} / \mathrm{mL}$ ). Principally, the D-dimer levels were noted during the first assessment immediately after admission, according to the local 
practice of each center, i.e., either immediately in the emergency room at admission or in the days following admission.

We further categorized the subjects into groups based on the antithrombotic agents prescribed upon discharge (antiplatelets alone vs. OACs with or without antiplatelets; warfarin vs. NOACs; dual antithrombotics vs. OACs alone). We analyzed the efficacy of antithrombotic regimens for secondary prevention of recurrent stroke and their safety according to baseline D-dimer levels on the stroke index in the population that survived and underwent antithrombotic treatment both during hospitalization and at discharge. Additionally, we concomitantly compared the results of the enrolled patients with atherosclerosis with the results of those without atherosclerosis and those who did not meet the inclusion criteria, to assess the likelihood of selection bias. The antithrombotics were administered at the discretion of the treating physician. We included all varieties of NOACs (dabigatran, apixaban, rivaroxaban, and edoxaban).

\subsection{Ethics Statement}

This study was approved by the institutional review boards of all participating centers. The necessity to obtain patient consent was waived since our procedures and protocols adequately protected their anonymity. All clinical and laboratory investigations described in this study were conducted according to the principles expressed in the Declaration of Helsinki. All supporting data within the article is available from the corresponding author on reasonable request.

\subsection{Protocol and Outcome Measurements}

The primary outcome measure was the occurrence of recurrent ischemic stroke according to baseline D-dimer levels and the antithrombotic therapies over a 3-year period. Recurrent ischemic stroke was defined as the sudden development of a new focal neurologic deficit or the worsening of a pre-existing one after the index stroke event, evidenced by the presence of new ischemic lesions on brain imaging (magnetic resonance imaging or computed tomography). Key secondary outcomes included the occurrence of any stroke, intracranial hemorrhage (ICH), acute coronary syndrome (ACS), and major extracranial bleeding. ACS was defined as myocardial infarction (MI), unstable angina, or ischemia-associated sudden cardiac death.

Clinical information for outcomes after discharge was prospectively obtained from all patients, either during their routine clinic visits or by corresponding with them or their caregivers over a 3-year period. Adherence to prescribed medication was assessed via interviews three months after the index event using the six-item modified Morisky Medication Adherence Scale at the largest center [9]. High adherence was defined as motivation and knowledge domain scores of $\geq 2$. As recommended by current guidelines, left ventricular (LV) diastolic dysfunction was defined with an algorithm for grading LV diastolic function in patients with AF [10]. Congestive heart failure was defined as a clinical syndrome that was diagnosed by a cardiologist, having a New York Heart Association class II or higher [11]. Baseline clinical and laboratory data about the history of risk factors that were etiologically associated with atherosclerosis and AF, including hypertension, dyslipidemia, diabetes mellitus, obesity, and current smoking habits was collected from all patients [12].

\subsection{Statistical Analysis}

Differences between the groups based on the use of antithrombotic agents were analyzed using Student's $t$-tests or the Kruskal-Wallis test for continuous variables. The chi-square $\left(\chi^{2}\right)$ test or Fisher's exact test was used to analyze categorical variables. A $p$ value of $<0.05$ was considered statistically significant. Unadjusted associations for antithrombotic therapy and risks for clinical outcomes were obtained using Kaplan-Meier curves throughout the study period to account for censoring.

Cox proportional hazard regression models were subsequently constructed to calculate adjusted hazard ratios (HRs) and 95\% confidence intervals (CIs), for clinical outcomes concerning antithrombotic therapy, according to the baseline D-dimer levels. Based on the clinical significance and the results 
of previous studies, several adjustments were made to incorporate information from the following variables: Age, sex, hypertension, dyslipidemia, diabetes mellitus, current smoking, congestive heart failure, prior history of stroke or transient ischemic attack (TIA), reperfusion therapies, and initial National Institutes of Health Stroke Scale (NIHSS) scores. We then performed a subgroup analysis to study the heterogeneity of effects associated with D-dimer levels and antithrombotic therapy on the risk of recurrent ischemic stroke according to age, sex, AF type, and the reperfusion therapy, which could influence D-dimer levels. $p$ Values of $<0.05$ were considered statistically significant in the Cox proportional hazard regression analyses. Statistical analyses were performed using SPSS 23.0 (IBM Corporation, Armonk, NY, USA), SAS v. 9.4 (SAS Institute Inc., Cary, NC, USA), and R 3.3.1 (R Foundation for Statistical Computing, Vienna, Austria).

\section{Results}

\subsection{Patient Characteristics}

Among the 3213 patients registered in the database, the study population was comprised of 1441 patients with AF-related stroke and atherosclerotic diseases (Figure 1). Patients with atherosclerosis demonstrated a history of susceptibility to risk factors such as hypertension, diabetes mellitus, and higher low-density lipoprotein (LDL) and lower high-density lipoprotein (HDL) cholesterol levels than the excluded patients without atherosclerosis (Table S1). There were no notable differences in age and sex between those who were included and excluded. The majority of AF-related stroke patients without atherosclerosis, who were excluded from the study, were treated with anticoagulants $(n=778 / 815,95.5 \%)$.

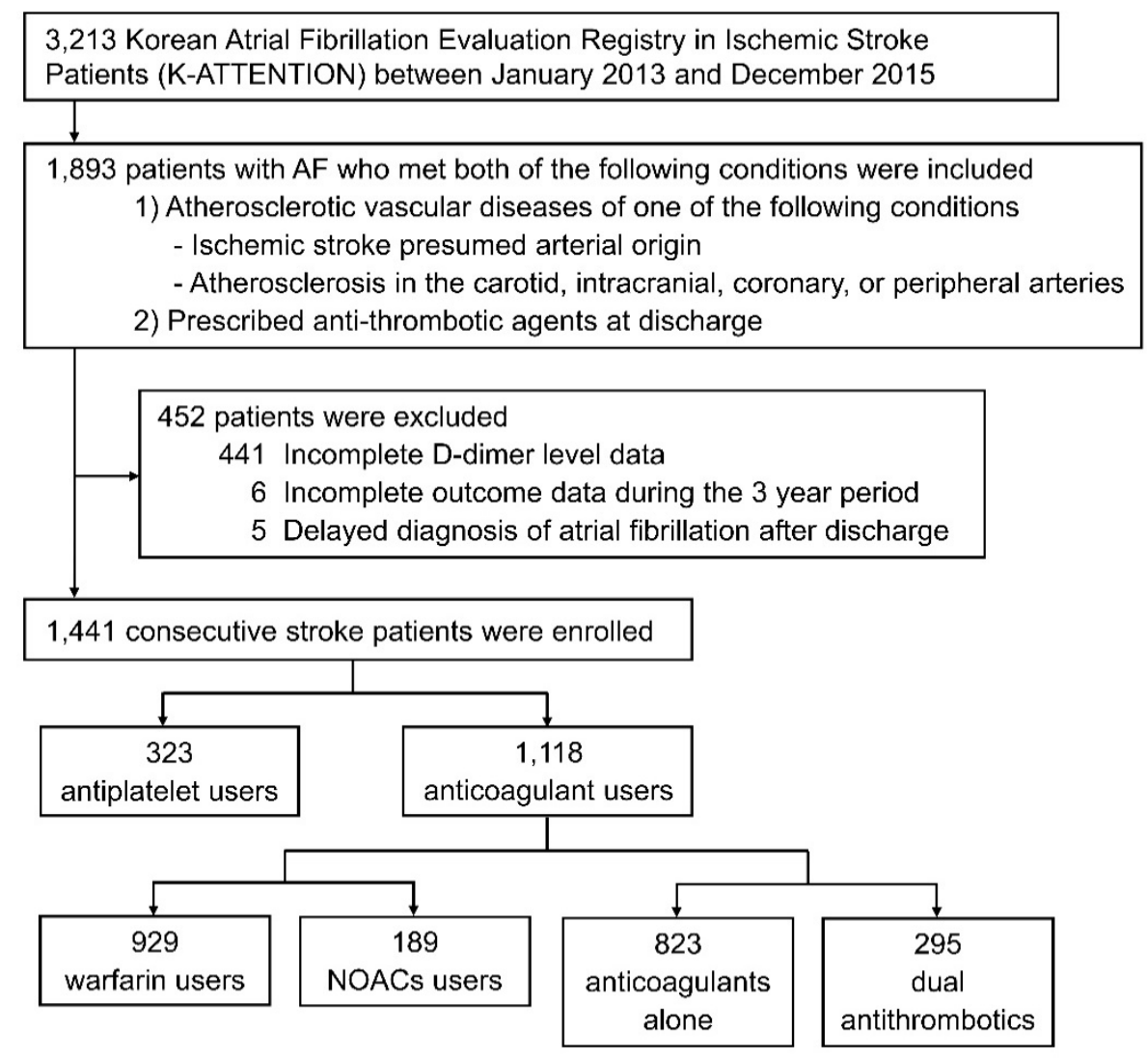

Figure 1. Flow chart of the study enrolment process.

The median follow-up duration was 17.6 months (interquartile range, 4.4-32.6 months). The mean age of the study population was 73.5 years (SD 9.7), and 750 (52.0\%) patients were men. The clinical 
and biochemical characteristics of the patients who presented high $(\geq 2 \mu \mathrm{g} / \mathrm{mL})$ baseline D-dimer levels $(n=515,35.7 \%)$ and low $(<2 \mu \mathrm{g} / \mathrm{mL}) \mathrm{D}$-dimer levels $(n=926,64.3 \%)$ are provided in Table 1 Compared to the low D-dimer group, the high D-dimer group was more likely to have higher $\mathrm{CHA}_{2} \mathrm{DS}_{2}-\mathrm{VASc}$ (Congestive heart failure, Hypertension, Age $\geq 75$ years [doubled], Diabetes mellitus, Prior Stroke or TIA or Thromboembolism [doubled], Vascular disease, Age 65-74 years, Sex category) and initial NIHSS scores, and a higher incidence of sustained (persistent) AF instead of paroxysmal AF, along with valvular diseases, reperfusion therapies, and lower creatinine clearance. Intracranial atherosclerosis and a history of dyslipidemia were more common in the low D-dimer group than the high D-dimer group.

Table 1. Baseline clinical and biochemical characteristics according to the baseline D-dimer levels.

\begin{tabular}{|c|c|c|c|c|}
\hline & $\begin{array}{l}\text { Patients with D-Dimer } \\
\text { Levels of }<2.0 \mu \mathrm{g} / \mathrm{mL} \\
\qquad(n=926)\end{array}$ & $\begin{array}{l}\text { Patients with D-Dimer } \\
\text { Levels of } \geq 2.0 \mu \mathrm{g} / \mathrm{mL} \\
\qquad(n=515)\end{array}$ & $\begin{array}{c}\text { Total } \\
(n=1441)\end{array}$ & $p$ Value \\
\hline Age, years $($ mean $\pm S D)$ & $73.6 \pm 9.6$ & $73.2 \pm 9.8$ & $73.5 \pm 9.7$ & 0.454 \\
\hline Male, $n(\%)$ & $475(51.3)$ & $275(53.4)$ & $750(52.0)$ & 0.477 \\
\hline Valvular AF, $n(\%)$ & $23(2.5)$ & $8(1.6)$ & $31(2.2)$ & 0.328 \\
\hline AF type, $n(\%)$ & & & & $<0.001$ \\
\hline Paroxysmal AF & $578(62.4)$ & $260(50.5)$ & $838(58.2)$ & \\
\hline Sustained AF & $348(37.6)$ & $255(49.5)$ & $603(41.8)$ & \\
\hline \multirow[t]{2}{*}{ Body mass index } & $23.2 \pm 3.3$ & $23.4 \pm 3.4$ & $23.3 \pm 3.3$ & 0.465 \\
\hline & \multicolumn{2}{|c|}{ History of Risk Factors, $n(\%)$} & & \\
\hline Hypertension & $650(70.2)$ & $376(73.0)$ & $1026(71.2)$ & 0.284 \\
\hline Diabetes mellitus & $268(28.9)$ & $142(27.6)$ & $410(28.5)$ & 0.623 \\
\hline Dyslipidemia & $217(23.4)$ & $96(18.6)$ & $313(21.7)$ & 0.041 \\
\hline Congestive heart failure & $34(3.7)$ & $22(4.3)$ & $56(3.9)$ & 0.673 \\
\hline Current smoking & $142(15.3)$ & $62(12.0)$ & $204(14.2)$ & 0.101 \\
\hline \multirow[t]{2}{*}{ Prior stroke or TIA } & $276(29.8)$ & $178(34.6)$ & $454(31.5)$ & 0.071 \\
\hline & \multicolumn{3}{|c|}{ Biochemical Variables (mean \pm SD) } & \\
\hline D-dimer, $\mu \mathrm{g} / \mathrm{mL}$ & $0.8 \pm 0.5$ & $6.1 \pm 6.5$ & $2.7 \pm 4.6$ & $<0.001$ \\
\hline LDL-C, mg/dL & $98.4 \pm 33.9$ & $97.6 \pm 34.6$ & $98.1 \pm 34.1$ & 0.708 \\
\hline Triglyceride, $\mathrm{mg} / \mathrm{dL}$ & $99.4 \pm 63.1$ & $92.4 \pm 48.2$ & $96.9 \pm 58.3$ & 0.019 \\
\hline HDL-C, mg/dL & $48.3 \pm 19.2$ & $47.0 \pm 17.1$ & $47.8 \pm 18.5$ & 0.186 \\
\hline Glycated hemoglobin, \% & $6.1 \pm 2.0$ & $5.9 \pm 1.0$ & $6.0 \pm 1.7$ & 0.078 \\
\hline Admission glucose, $\mathrm{mg} / \mathrm{dL}$ & $139.2 \pm 81.2$ & $137.8 \pm 48.5$ & $138.7 \pm 71.2$ & 0.687 \\
\hline Creatinine clearance, $\mathrm{mL} / \mathrm{min}$ & $65.6 \pm 28.0$ & $56.3 \pm 27.8$ & $62.3 \pm 28.3$ & $<0.001$ \\
\hline Pre-stroke mRS, median (IQR) & $0(0 ; 1)$ & $0(0 ; 2)$ & $0(0 ; 1)$ & 0.054 \\
\hline Initial NIHSS, median (IQR) & $6(2 ; 13)$ & $13(6 ; 18)$ & $9(2 ; 15)$ & $<0.001$ \\
\hline Intravenous alteplase, $n(\%)$ & $159(17.2)$ & $168(32.6)$ & $327(22.7)$ & $<0.001$ \\
\hline Mechanical thrombectomy, $n(\%)$ & $120(13.0)$ & $87(16.9)$ & $207(14.4)$ & 0.050 \\
\hline $\mathrm{CHA}_{2} \mathrm{DS}_{2}$-VASc score, median (IQR) & $5(4 ; 6)$ & $5(4 ; 6)$ & $5(4 ; 6)$ & 0.001 \\
\hline $\mathrm{CHA}_{2} \mathrm{DS}_{2}-\mathrm{VASc} \geq 5, n(\%)$ & $552(59.6)$ & $372(72.2)$ & $924(64.1)$ & $<0.001$ \\
\hline \multirow[t]{2}{*}{ AIS presumed arterial origin, $n(\%)$} & $276(29.8)$ & $162(31.5)$ & $438(30.4)$ & 0.553 \\
\hline & \multicolumn{3}{|c|}{ Large Artery Atherosclerosis, $n(\%)$} & \\
\hline Carotid atherosclerosis & $260(31.7)$ & $154(32.7)$ & $414(32.1)$ & 0.772 \\
\hline Intracranial atherosclerosis & $648(78.0)$ & $314(65.4)$ & $962(73.4)$ & $<0.001$ \\
\hline Coronary atherosclerosis & $144(15.6)$ & $69(13.4)$ & $213(14.8)$ & 0.305 \\
\hline \multirow[t]{2}{*}{ Peripheral atherosclerosis } & $13(1.4)$ & $8(1.6)$ & $21(1.5)$ & 1.000 \\
\hline & \multicolumn{3}{|c|}{ Transthoracic Echocardiographic Findings * } & \\
\hline LA thrombus, $n(\%)$ & $11(1.3)$ & $11(2.3)$ & $22(1.7)$ & 0.259 \\
\hline LA volume index, $\mathrm{mL} / \mathrm{m}^{2}$ & $66.0 \pm 24.8$ & $67.0 \pm 24.9$ & $66.3 \pm 24.8$ & 0.493 \\
\hline $\mathrm{LVEF}<50 \%, n(\%)$ & $122(14.5)$ & $74(15.6)$ & $196(14.9)$ & 0.677 \\
\hline LV diastolic dysfunction, $n(\%)$ & $596(71.2)$ & $343(72.3)$ & $939(71.6)$ & 0.727 \\
\hline Moderate-severe AR, $n(\%)$ & $9(1.1)$ & $13(2.7)$ & $22(1.7)$ & 0.042 \\
\hline Moderate-severe MR, $n(\%)$ & $26(3.1)$ & $23(4.9)$ & 49 (3.8) & 0.149 \\
\hline
\end{tabular}

* Data for 131 patients (90 patients in the low D-dimer group and 41 patients in the high D-dimer group) was unavailable. AF, atrial fibrillation; TIA, transient ischemic attack; SD, standard deviation; LDL-C, low-density lipoprotein cholesterol; HDL-C, high-density lipoprotein cholesterol; mRS, modified Rankin Scale; NIHSS, National Institutes of Health Stroke Scale; IQR, interquartile ranges; AIS, acute ischemic stroke; LA, left atrium; LVEF, left ventricular ejection fraction; $\mathrm{LV}$, left ventricle; $\mathrm{AR}$, aortic regurgitation; $\mathrm{MR}$, mitral regurgitation.

Table S2 contains information regarding the baseline characteristics of the patients who received antiplatelet $(n=323,22.4 \%)$ and anticoagulant therapies $(n=1118,77.6 \%)$ for the groups that underwent antithrombotic therapy. The anticoagulant group showed greater susceptibility for higher rates of sustained AF, a history of dyslipidemia, congestive heart failure, higher triglyceride levels, and lower initial NIHSS scores than the antiplatelet group. Carotid atherosclerosis or symptomatic atherosclerosis was more common in the antiplatelet group, and intracranial or peripheral atherosclerosis was higher 
in the anticoagulant group; however, the differences were not significant. The baseline D-dimer levels were similar in both treatment groups. Among those treated with NOACs (189 patients), dabigatran was the most used (in 74 patients). The NOACs used were identical for every group according to the baseline D-dimer levels $(p=0.148)$. Information regarding adherence to the prescribed medication after three months was available for patients at the largest center, and $84.1 \%(422 / 502)$ of these patients demonstrated high adherence to the same antithrombotic therapy.

\subsection{Clinical Outcomes}

Overall, 87 patients were identified with recurrent ischemic stroke during the follow-up period (Table S3). There was no difference in the cumulative incidence of recurrent ischemic stroke between the patients after categorizing them into two groups based on the following D-dimer levels: $0.5 \mu \mathrm{g} / \mathrm{mL}$ and $1 \mu \mathrm{g} / \mathrm{mL}$ (log-rank $p=0.672$ and $p=0.761$, respectively; Figure 2A,B). However, patients with high baseline D-dimer levels ( $\geq 2 \mu \mathrm{g} / \mathrm{mL}$ ) were at a higher risk for recurrent ischemic stroke than were those with low D-dimer levels $(<2 \mu \mathrm{g} / \mathrm{mL}$; log-rank $p=0.049$; Figure $2 \mathrm{C})$. Similarly, those with high baseline D-dimer levels $(\geq 3 \mu \mathrm{g} / \mathrm{mL})$, were at a greater risk for recurrent ischemic stroke (log-rank $p=0.014$; Figure 2D).

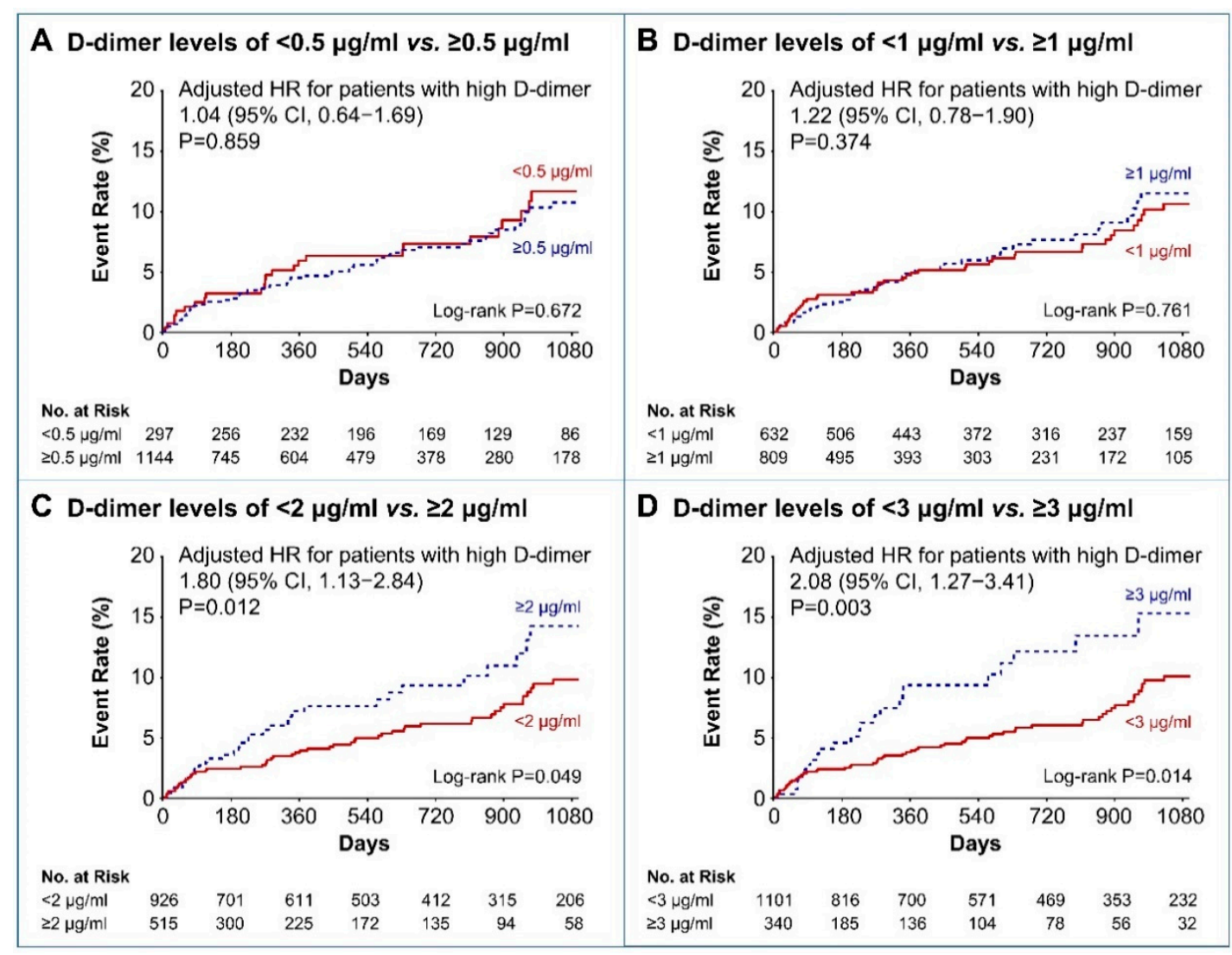

Figure 2. Kaplan-Meier curves and adjusted hazard ratios for recurrent ischemic stroke according to the baseline D-dimer levels. HR, hazard ratio; CI, confidence interval.

Baseline high D-dimer levels $\geq 2 \mu \mathrm{g} / \mathrm{mL}$ and $\geq 3 \mu \mathrm{g} / \mathrm{mL}$ remained significantly associated with a higher risk for recurrent ischemic stroke after being adjusted for confounders using the multivariable Cox regression analyses (HR, 1.80; 95\% CI, 1.13-2.84; $p=0.012$; and HR, 2.08; 95\% CI, 1.27-3.41; $p=0.003$, respectively; Figure 2C,D). The risk for any stroke was also higher in patients with D-dimer levels $\geq 2 \mu \mathrm{g} / \mathrm{mL}$ than in those with D-dimer levels $<2 \mu \mathrm{g} / \mathrm{mL}$ after adjusting for confounders (HR, 1.54; 95\% CI 1.01-2.37; $p=0.044$; Figure 3A). The risk factors associated with ICH, ACS, and major bleeding were not significantly different between the high and low D-dimer groups (Figure 3B-D). 


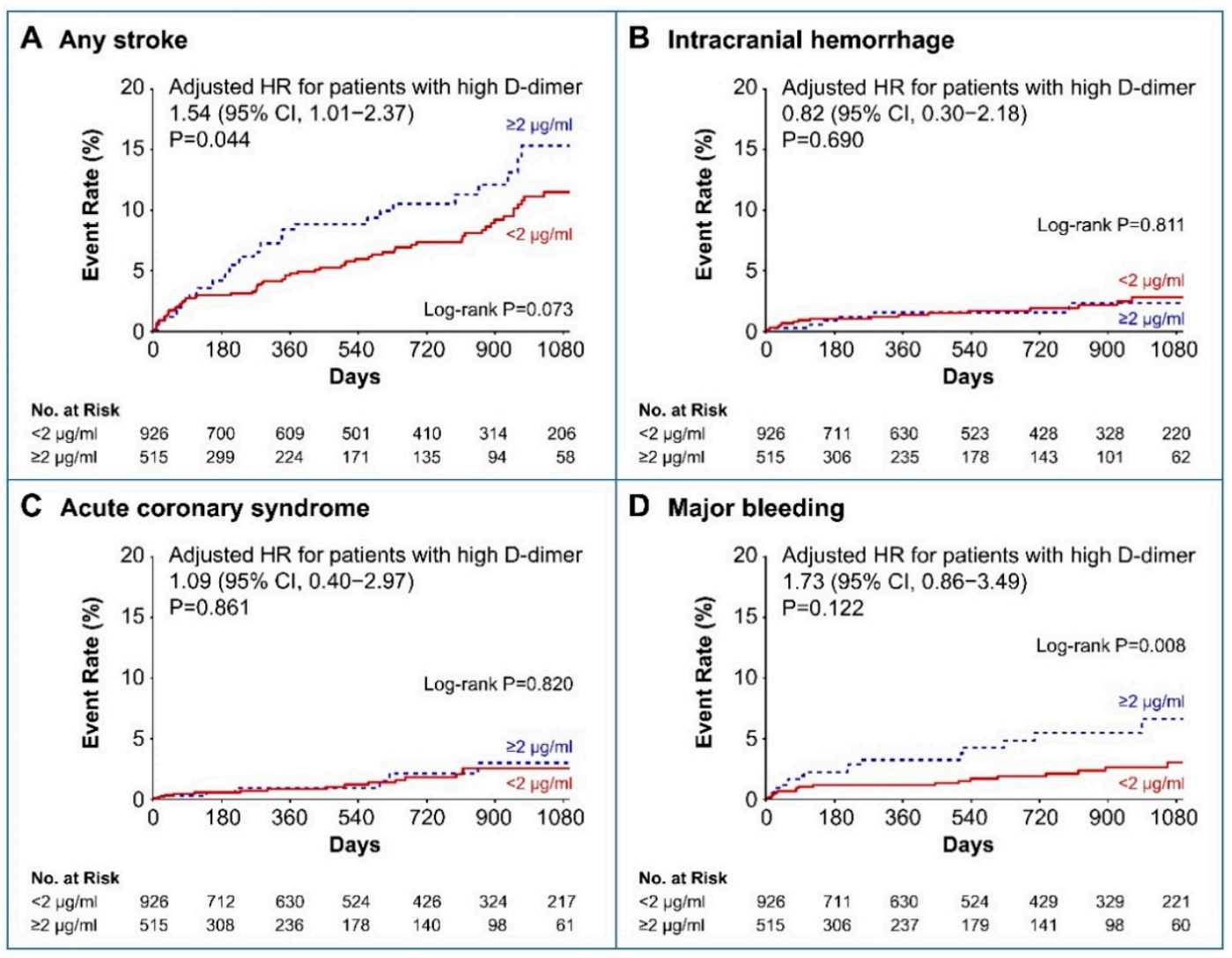

Figure 3. Kaplan-Meier curves and adjusted hazard ratios for secondary outcomes of (A) any stroke, (B) intracranial hemorrhage, (C) acute coronary syndrome, and (D) major bleeding according to the baseline D-dimer levels. HR, hazard ratio; CI, confidence interval.

Figure 4 illustrates the results of the Kaplan-Meier analysis, which indicated that antiplatelets and OACs for secondary prevention of recurrent ischemic stroke, according to baseline D-dimer levels on the stroke index, were significantly different in patients having AF-related stroke and atherosclerotic diseases. Crude incidence rates of recurrent ischemic strokes were similar between the OAC group and the antiplatelet group among all subjects ( 3.95 per 100 person-years vs. 5.07 per 100 person-years; unadjusted HRs for the use of anticoagulants $0.81 ; 95 \% \mathrm{CI}, 0.48-1.36 ; p=0.421$, respectively; Figure $4 \mathrm{~A}$ and Table S3). However, compared to antiplatelets, OACs reduced the risk of recurrent ischemic stroke in patients with higher D-dimer levels (Figure 4B-F). High D-dimer level ( $\geq 2 \mu \mathrm{g} / \mathrm{mL}$ ) patients, who were at a higher risk for recurrent ischemic stroke, demonstrated significantly lower risk of recurrent ischemic stroke in the OACs group than in the antiplatelet group (4.74 per 100 person-years vs. 11.10 per 100 person-years; unadjusted HRs for the use of OACs $0.44 ; 95 \% \mathrm{CI}, 0.21-0.94 ; p=0.028$, respectively; Figure 4E and Table S3).

Regarding key secondary outcomes, there was no significant difference between the OAC and antiplatelet groups regarding the occurrence of any stroke, ICH, ACS, or major bleeding in all subjects (Figure S1 and Table S3). However, patients with high D-dimer levels ( $\geq 2 \mu \mathrm{g} / \mathrm{mL}$ ) who were at a higher risk for recurrent ischemic stroke demonstrated a lower incidence of any stroke in the OAC group than in the antiplatelet group (5.37 per 100 person-years vs. 12.27 per 100 person-years; HR, $0.44 ; 95 \%$ CI, 0.220-0.93; $p=0.026$, respectively; Figure S2 and Table S3). Incidences of the individual outcomes regarding ICH, ACS, and major bleeding were not significantly different between the OAC and antiplatelet groups (Figures S2 and S3, and Table S3).

To better identify the effect of antithrombotic therapies on the risk for recurrent ischemic stroke in patients with AF-related stroke and atherosclerotic diseases, we adjusted for confounders using multivariable Cox regression analyses. In all patients with AF-related stroke and atherosclerotic 
diseases, there were no significant differences between the risks for recurrent ischemic stroke (HR, 0.78; 95\% CI, 0.46-1.32; $p=0.369)$, any stroke (HR, 0.83; 95\% CI, 0.51-1.37; $p=0.483)$, ICH (HR, $1.18 ; 95 \% \mathrm{CI}$, $0.34-4.09 ; p=0.787)$, ACS (HR, 0.85; 95\% CI, 0.28-2.57; $p=0.776)$, and major bleeding (HR, $0.84 ; 95 \% \mathrm{CI}$, $0.34-2.07 ; p=0.719$ ) among the antiplatelets (the reference group) and OAC groups (Figure 5A).



Figure 4. Kaplan-Meier curves for recurrent ischemic stroke according to antithrombotic therapy according to the baseline D-dimer levels. HR, hazard ratio; CI, confidence interval.

However, patients with high D-dimer levels $(\geq 2 \mu \mathrm{g} / \mathrm{mL})$ receiving anticoagulant therapy had a significantly lower risk for recurrent ischemic stroke (HR, 0.40; 95\% CI, 0.18-0.87; $p=0.022$; Figure 5B) than those receiving antiplatelet therapy. Similarly, those receiving anticoagulants were at a lower risk for any stroke among the secondary outcomes (HR, $0.43 ; 95 \% \mathrm{CI}, 0.21-0.89 ; p=0.025$; Figure 5B). In contrast, there were no differences in the risks for ICH (HR, 0.33; $95 \% \mathrm{CI}, 0.05-2.19 ; p=0.252)$, ACS (HR, 0.92; 95\% CI, 0.08-11.07; $p=0.953)$, and major bleeding (HR, 1.01; 95\% CI, 0.28-3.63; $p=0.991)$ among those that underwent antiplatelet (the reference group) and OAC treatment (Figure 5B). 
A All patients

$$
\begin{array}{r}
\text { Recurrent ischemic stroke } \\
\text { Any stroke } \\
\text { Intracranial hemorrhage } \\
\text { Acute coronary syndrome } \\
\text { Major bleeding }
\end{array}
$$

Adjusted HR $(95 \% \mathrm{Cl}) \quad$ P Value

$\begin{array}{ll}0.78(0.46-1.32) & 0.369 \\ 0.83(0.51-1.37) & 0.483 \\ 1.18(0.34-4.09) & 0.787 \\ 0.85(0.28-2.57) & 0.776 \\ 0.84(0.34-2.07) & 0.719\end{array}$

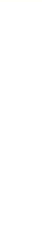

B Patients with D-dimer levels of $\geq 2.0 \mu \mathrm{g} / \mathrm{ml}$ Adjusted $\mathrm{HR}(95 \% \mathrm{Cl})$

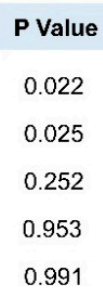

$\begin{array}{rll}\text { Recurrent ischemic stroke } & 0.40(0.18-0.87) & 0.022 \\ \text { Any stroke } & 0.43(0.21-0.89) & 0.025 \\ \text { Intracranial hemorrhage } & 0.33(0.05-2.19) & 0.252 \\ \text { Acute coronary syndrome } & 0.92(0.08-11.07) & 0.953 \\ \text { Major bleeding } & 1.01(0.28-3.63) & 0.991\end{array}$

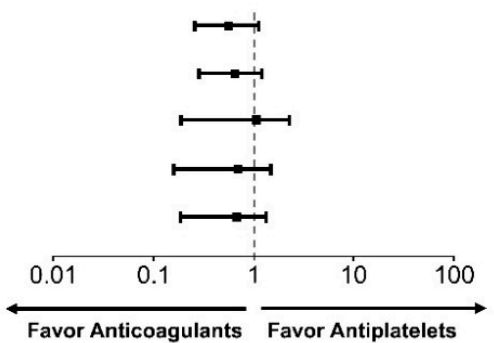

Favor Anticoagulants Favor Antiplatelets

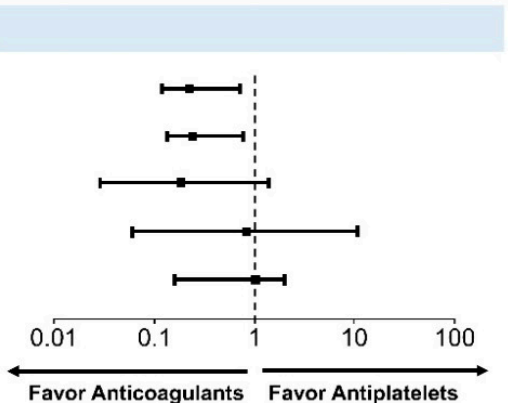

Figure 5. Cox proportional hazards regression analyses for primary and secondary outcomes. Adjusted hazard ratios for anticoagulant therapy compared with antiplatelet therapy in all patients (A) and patients with D-dimer levels of $\geq 2.0 \mu \mathrm{g} / \mathrm{mL}$ (B).

We performed tests to analyze differences in the effects of anticoagulants to prevent recurrent ischemic stroke between patients with and without combined AF and atherosclerosis (included and excluded patients, respectively). Our results reported no significant difference in the effects of anticoagulants on the primary outcome in patients with and without combined AF and atherosclerosis $\left(p_{\text {interaction }}=0.868\right.$; Figure 6$)$. The therapeutic effects of anticoagulant in patients with baseline D-dimer levels $>2 \mu \mathrm{g} / \mathrm{mL}$, in comparison those of antiplatelet, were similar in patients with and without combined AF and atherosclerosis ( $p_{\text {interaction }}=0.327$; Figure 6 ).

\section{No. of Adjusted Hazard Ratios for Recurrent P Value for Patients Ischemic Stroke (95\% Confidence Interval) Interaction}

\section{A All patients}

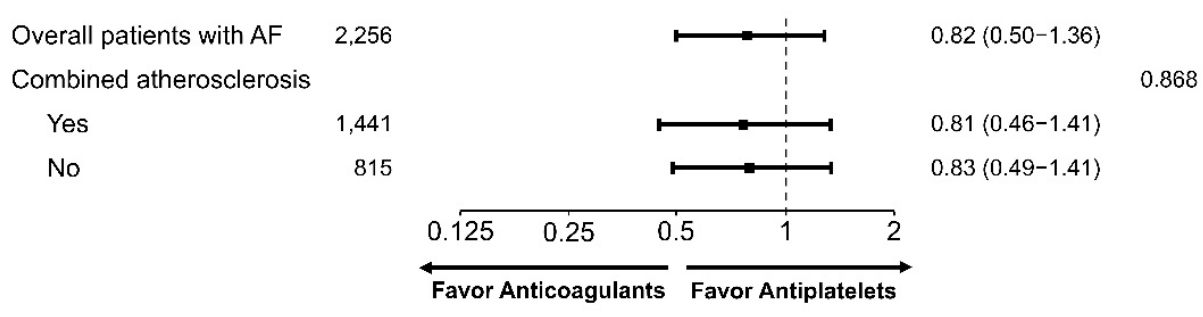

\section{B Patients with D-dimer levels of $\geq 2.0 \mu \mathrm{g} / \mathrm{ml}$}

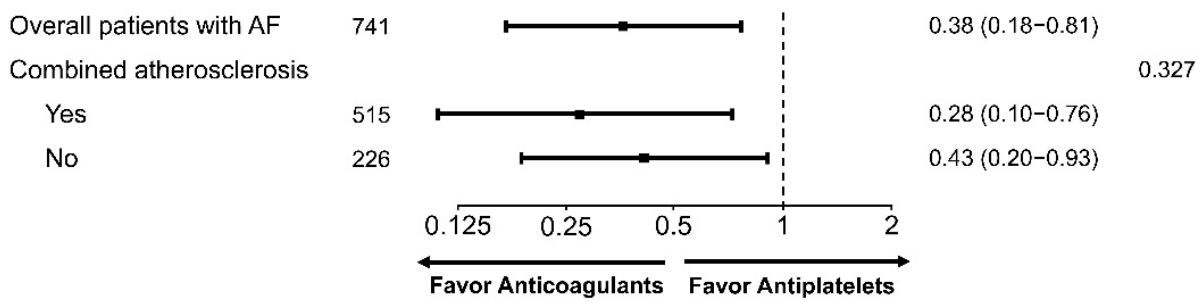

Figure 6. Adjusted hazard ratios for a comparison between anticoagulant and antiplatelet therapy in all patients with and without atherosclerosis (A) and a subgroup of patients with D-dimer levels $\geq 2.0 \mu \mathrm{g} / \mathrm{mL}(\mathbf{B})$. AF, atrial fibrillation. 
Considering the presence of a significant difference among the AF types based on the D-dimer group, we evaluated a subgroup of patients with the paroxysmal and sustained AF separately. Among paroxysmal AF patients, the risk for recurrent stroke was higher in patients with higher D-dimer levels ( $\geq 2 \mu \mathrm{g} / \mathrm{mL})$ than in those with relatively lower D-dimer levels $(<2 \mu \mathrm{g} / \mathrm{mL})$ after adjusting for confounders (HR, 2.39; 95\% CI 1.26-4.52; $p=0.007$; Table S4). Patients with sustained AF who presented high baseline D-dimer levels ( $\geq 2 \mu \mathrm{g} / \mathrm{mL})$ and were administered anticoagulant therapy demonstrated a significantly lower risk for recurrent ischemic stroke than those who received antiplatelet therapy (HR, 0.17; 95\% CI, 0.04-0.62; $p=0.007$; Table S5). However, subgroup analyses revealed that the risk of high D-dimer levels $(\geq 2.0 \mu \mathrm{g} / \mathrm{mL})$ and beneficial effects of anticoagulant therapy in comparison with antiplatelet therapy on the risk of recurrent ischemic stroke in patients with high D-dimer levels $(\geq 2.0 \mu \mathrm{g} / \mathrm{mL}$ ) were uniform across all subgroups. This included both AF type and reperfusion therapy (Figure 7). The adjusted HRs for anticoagulant were not significant for male and female patients, older patients (age $>75$ years), patients with paroxysmal $\mathrm{AF}$, and patients who underwent reperfusion therapy; however, according to the subgroups there was no evidence of heterogeneity associated with the therapeutic effects of administering anticoagulants when compared with antiplatelet treatment (Figure 7).

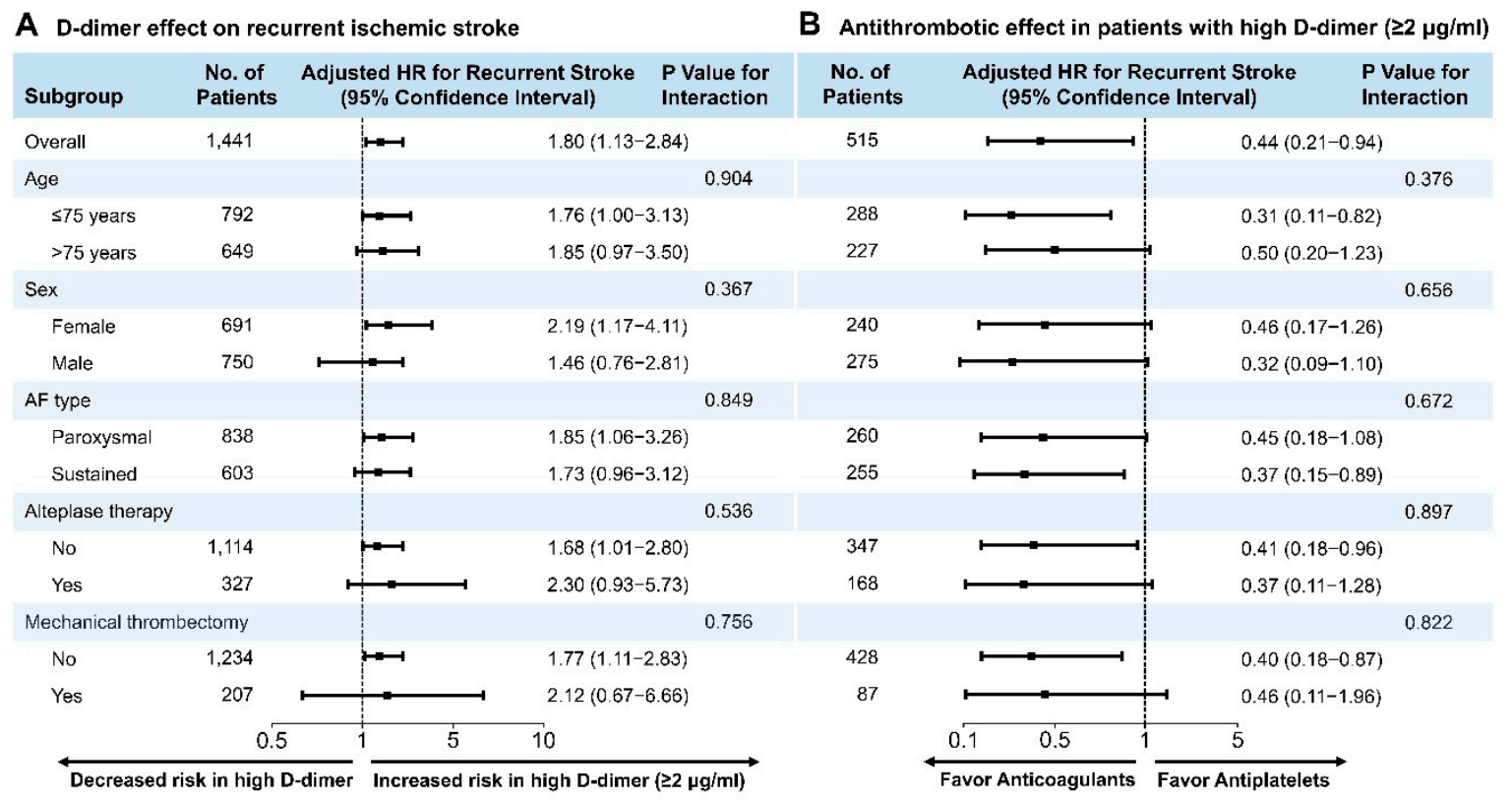

Figure 7. Subgroup analyses of recurrent stroke. The forest plot shows the differences in hazards ratio for high D-dimer levels ( $\geq 2.0 \mu \mathrm{g} / \mathrm{mL}$ ) in all patients with combined AF and atherosclerosis (A) and a comparison between anticoagulant and antiplatelet therapy in patients with D-dimer levels $\geq 2.0 \mu \mathrm{g} / \mathrm{mL}(\mathbf{B})$. AF, atrial fibrillation.

We subsequently performed tests to analyze the differences between warfarin and NOACs as methods to prevent recurrent ischemic stroke and any stroke within the OAC groups. We also analyzed whether the dual antithrombotic therapy using both antiplatelets and OACs is more effective than OACs alone in patients having D-dimer levels of $\geq 2 \mu \mathrm{g} / \mathrm{mL}$ and at a higher risk for recurrent ischemic stroke. The mean time in the therapeutic range of warfarin was $50.9 \%$ (SD 24.0\%). There were no differences in the risks of recurrent ischemic stroke (adjusted HR, 1.09; 95\% CI, 0.35-3.30; $p=0.879$ ) and any stroke (HR, $0.93 ; 95 \% \mathrm{CI}, 0.31-2.78 ; p=0.901)$ between the use of warfarin (the reference group) and NOACs in patients with D-dimer levels of $\geq 2 \mu \mathrm{g} / \mathrm{mL}$ (Figure S4). The risks of recurrent ischemic stroke (HR, 1.43; 95\% CI, 0.57-3.57; $p=0.444)$ and any stroke (HR, $1.21 ; 95 \% \mathrm{CI}, 0.49-2.94 ; p=0.673)$ were also similar in patients treated with dual antithrombotic therapy with antiplatelets and OACs 
compared to those treated with OACs alone in patients with AF-related stroke and atherosclerotic diseases with high D-dimer levels ( $\geq 2 \mu \mathrm{g} / \mathrm{mL}$ ) who were at a higher risk for recurrence (Figure S4).

\section{Discussion}

To the best of our knowledge, this is the first study to highlight the effects of D-dimer levels on the risk of recurrent stroke in a large, nationwide, population of patients with AF-related stroke and atherosclerotic diseases. Our study demonstrates that high D-dimer levels are independently associated with the risk of recurrent stroke in these patients. Furthermore, this is the first clinically applicable study on the efficacy and safety of different antithrombotic therapies according to baseline D-dimer levels. We found no difference between the effects of antiplatelets and anticoagulants in the prevention of recurrent ischemic stroke in all subjects or patients with low baseline D-dimer levels. However, we successfully demonstrated that compared with antiplatelets, anticoagulants were significantly associated with a lower risk of recurrent stroke in patients with D-dimer levels of $\geq 2 \mu \mathrm{g} / \mathrm{mL}$. Therefore, high D-dimer levels would facilitate the identification of patients who are more likely to benefit from anticoagulants than antiplatelets for secondary prevention of stroke in those who have a high risk for recurrent stroke with both cardioembolic and non-cardioembolic causes.

D-dimer is typically formed post fibrin degradation and is, therefore, considered as a marker of hypercoagulable states associated with thrombus formation and resolution [5,13]. AF patients demonstrate increased D-dimer levels, which is related to the development of the left atrial thrombus [13,14]. Therefore, a causal association between high D-dimer levels and the risk for stroke is biologically plausible in AF patients $[13,14]$. Until recently, several studies had described the prognostic value of D-dimer levels for primary prevention of stroke in patients with AF [6,7]. Higher baseline D-dimer levels were related to a greater risk for stroke in AF patients.

Considering secondary prevention, a previous study reported that D-dimer levels were not typical indicators of recurrent stroke in patients with AF-related stroke [15]. However, this study was performed on relatively few patients $(n=382)$, and the evaluation of critical clinical outcomes using survival analysis over time was not systematically investigated [15]. Alternatively, the present study involved a comparatively larger cohort of patients with AF-related stroke, and we recently considered developed treatments for stroke such as mechanical thrombectomy and NOACs, and the various etiologies such as atherosclerotic disease that can accompany AF. This large-scale, clinically applicable, nationwide study was the first to demonstrate the prognostic value of high D-dimer levels for recurrent stroke in patients with AF-related stroke and atherosclerosis. Recently, a biomarker-based risk score for predicting stroke was proposed for AF patients [14,15]. Biomarkers, including high-sensitivity troponin, natriuretic peptide, and free fatty acid were independently associated with risk for stroke in AF patients [16-18]. Our results suggest D-dimer levels as a risk assessment biomarker to further refine recurrent stroke risk in patients with AF-related stroke and atherosclerosis [17].

Previous studies have reported that D-dimer levels were significantly higher in patients with cardioembolism than in those with other subtypes of ischemic stroke $[19,20]$. We noted that among patients with AF-related stroke, those with high D-dimer levels had a higher $\mathrm{CHA}_{2} \mathrm{DS}_{2}$-VASc score and were more likely to have sustained (persistent) AF and valvular heart diseases. High CHA2DS2-VASc score and valvular heart diseases are important predictors of recurrence in patients with stroke [21]. Furthermore, sustained AF could be associated with a higher risk of stroke or systemic embolism than paroxysmal AF [22,23]. Cardiogenic cerebral embolism in AF patients is typically caused by the formation of a thrombus in the left atrial appendage (LAA) [24]. Therefore, in stroke patients with $\mathrm{AF}$, the function of LAA or the thrombus in LAA plays an important role in stroke recurrence [25]. As LAA function differs between paroxysmal and sustained AF, patients with sustained AF could have severer LAA blood stasis than those with paroxysmal AF [22,26]. Patients with a high baseline D-dimer level ( $\geq 2 \mu \mathrm{g} / \mathrm{mL}$ ) demonstrate significantly higher incidences of sustained AF, which may be one of the primary etiological factors for the association of a high D-dimer level with frequent stroke recurrence in our study. 
However, there were no significant differences in the thrombus and volume of the left atrium (LA) between the high and low D-dimer groups in our study, although high D-dimer group was more likely to have sustained AF. It is possible that the presence of an LA, particularly LAA, a thrombus, or dysfunction may have been underestimated since it was confirmed only by using transthoracic echocardiography (TTE) [27]. Previous studies have failed to detect LA thrombus using TTE until recently $[28,29]$. In other studies, the rate of LA thrombus detection using TTE is as low as approximately $1 \%$ in patients with AF-related stroke $[30,31]$. Since most patients with stroke in our study did not undergo transesophageal echocardiography (TEE) and LA thrombus was assessed only by TTE, it may appear that there is no difference among the D-dimer groups. However, a previous systematic review and meta-analysis reported that D-dimer had been significantly elevated in patients with a LA thrombus that was detected by TEE [32]. Therefore, if TEE was implemented, it would be possible that LA thrombus was observed more in the high D-dimer group, which had higher incidences of sustained AF.

Additionally, one of the reasons for the poor detection rates of LA thrombus could be due to the fact that it has been examined after thromboembolic events. TEE was better at detecting LA than TTE, particularly LAA thromus, and had a sensitivity and specificity of $99-100 \%$ [27,33]. However, LA thrombus was identified by TEE in only less than $50 \%$ of patients with newly recognized AF after the occurrence of an acute thromboembolic event, even if the TEE has 99-100\% accuracy [34]. In our study, D-dimer levels were noted immediately in the emergency room at admission; however, TTE was typically evaluated after few days of hospitalization. TTE was examined after the embolism had already come off and followed by the development of the thromboembolic events, but also after several days of antithrombotic treatment to resolve the embolism. A study previously reported that short-term anticoagulation resolved over $80 \%$ of cases of thrombus on follow-up TEE [35]. Therefore, LA thrombus may have been detected as low as there is no difference between the D-dimer groups in this study.

Considering another possible mechanism by which high D-dimer increases the risk of recurrent stroke, our study revealed that patients with high D-dimer levels demonstrated poor creatinine clearance. Chronic kidney diseases may be predictive of strokes, which may be partially due to the limitations of pharmacotherapies, including limited effects of antithrombotic treatments [36]. Furthermore, a study previously demonstrated that D-dimer could be a useful marker of activated coagulation in patients with decreased renal function [37]. Therefore, the distinct relationship observed between D-dimer levels and stroke recurrence in our study could be attributed to the fact that patients with high D-dimer levels had lower creatinine clearance.

Since high D-dimer levels are an indicator for hypercoagulable states, anticoagulant administration would be relatively more effective than antiplatelet treatment $[5,13]$. However, no studies have directly identified or reported an antithrombotic therapeutic modality that is more effective in patients with AF-related stroke and atherosclerotic diseases with elevated D-dimer levels. Our results demonstrated that anticoagulants were more effective than antiplatelets in preventing recurrent stroke; additionally, there were no differences between the two groups concerning the risk for ICH and major extracranial bleeding in patients with D-dimer levels of $\geq 2 \mu \mathrm{g} / \mathrm{mL}$. Therefore, this study highlights the importance of anticoagulant therapy in high D-dimer level patients with AF-related stroke and atherosclerotic diseases.

OACs are typically recommended for patients with AF-related stroke regardless of baseline D-dimer levels and the presence or absence of atherosclerotic diseases according to the current guidelines [3,38]. However, AF may not always be etiologically associated with ischemic stroke in patients with $\mathrm{AF}$ and atherosclerosis, and a study previously reported that one-sixth of strokes in patients with AF were unrelated to AF [39]. Moreover, the risk of bleeding due to OAC administration is significantly high, and it is also difficult to regulate the anticoagulation during blood sample measurement [40]. Therefore, physicians must carefully compare risks and benefits to determine the specific antithrombotic agent. Characteristically, several physicians are reluctant to prescribe OACs, due to which there are a large number of cases in actual clinical practice where antiplatelet agents have 
been administered to patients with AF-related stroke and atherosclerotic diseases [41,42]. Nevertheless, no studies have directly compared anticoagulation and antiplatelet therapy for secondary prevention of stroke in patients with $\mathrm{AF}$ and atherosclerotic diseases.

Previous studies have reported that $20-30 \%$ of patients admitted to hospitals with stroke and $\mathrm{AF}$ with an indication for OACs were taking antiplatelet agents alone until recently [41,42]. In our study, most AF-related stroke patients $(95.5 \%)$ without atherosclerosis were treated with anticoagulants. However, antiplatelet therapy was administered in $22.4 \%$ of patients suffering from a combination of AF-related stroke and atherosclerotic diseases. In this real-world study, there were no significant differences between antiplatelets and anticoagulants to prevent recurrent stroke in patients with low baseline D-dimer levels. Although anticoagulation therapy in patients with AF-related stroke and atherosclerotic diseases may still be the most reasonable antithrombotic option, this study does not provide adequate evidence to suggest that anticoagulant therapy is more effective than antiplatelet therapy in patients with low D-dimer levels $[3,38,40]$. High baseline D-dimer levels might identify patients with AF and atherosclerotic diseases as those who are more likely to benefit from OACs than antiplatelets for secondary prevention of stroke in risk-benefit stratification.

Among OACs, it is reasonable to hypothesize that using an effective anticoagulant therapeutic strategy may suppress D-dimer levels to a greater degree, which could further reduce the risk of stroke in patients with elevated D-dimer levels $[7,8,11]$. Previous studies reported that NOACs were more efficient in reducing D-dimer levels than warfarin [7,8]. However, no studies have investigated the efficacy of NOACs versus warfarin in patients with AF-related stroke and atherosclerotic diseases. This study does not indicate that NOACs are more effective than warfarin. It only suggests that OAC therapy itself, which can reduce D-dimer levels, is more important than its numerous variations, which could be used to diminish D-dimer levels even further [43]. However, considering the small proportion of patients in this study who underwent NOAC administration, it is imperative to conduct additional large-scale randomized controlled trials (RCTs) in the future.

Our study has several limitations; therefore, the findings must be interpreted with caution. First, as this is a prospectively registered observational study that involved retrospective data analysis and since there was no subject randomization, our data is prone to possible residual bias and significant methodologic shortcomings. Second, we did not collect detailed information on the changes in D-dimer levels after antithrombotic treatment during follow-up. Third, D-dimer value could change over time and be affected by anticoagulation or thrombolytic therapy $[7,8,11]$. There are different methods and time points to measure D-dimer levels, which may lead to substantial variations in the results. Therefore, the clinical prognostic value of D-dimer levels could not be confirmed. Fourth, we did not consider the potential effects of deep vein thrombosis, pulmonary thromboembolism, malignancy, and hematological diseases that could affect D-dimer levels [13]. In case the D-dimer level is elevated in patients with these diseases, and considering the preference of OAC therapeutic strategy, this may lead to the formation of a residual bias associated with these diseases [44]. Fifth, the possibility that LA, especially LAA, thrombus or dysfunction could be the primary cause of cardiogenic cerebral embolism in patients with AF may have been severely underestimated, since it was confirmed only by using TTE, but not TEE [33]. Sixth, we did not account for the following important risk factors that can lead to atherosclerosis and AF: emotional stress, diet, and physical inactivity $[12,45,46]$. Finally, we did not comply with the prescribed antithrombotics and ascertained the duration of using these antithrombotics via direct methods. Furthermore, information regarding adherence to medication after three months was available for the study population in the largest center only. However, approximately $84 \%$ of patients with available medication adherence information reported high adherence with the same antithrombotic therapy.

\section{Conclusions}

Our findings suggested that baseline D-dimer levels were associated with risk for recurrent stroke in patients with AF-related stroke and atherosclerotic diseases. Therefore, these results suggest that 
high D-dimer levels were a risk assessment biomarker for recurrent stroke in patients with AF-related stroke and atherosclerotic diseases. Among patients with high D-dimer levels $(\geq 2 \mu \mathrm{g} / \mathrm{mL})$ at higher risk for recurrent ischemic stroke, OAC therapy was relatively more effective in reducing the risk for recurrent stroke than antiplatelet therapy. These results support the use of OACs in patients with AF-related stroke and atherosclerotic diseases at high risk for recurrent stroke based on the risk assessment of baseline D-dimer levels. In addition, we found no difference between NOACs and warfarin as well as the dual antithrombotics and OACs alone in secondary prevention of recurrent ischemic stroke in patients with AF-related stroke and atherosclerotic diseases, suggesting that these may be reasonable therapeutic strategies. These findings require further investigation and confirmation in prospective RCTs.

Supplementary Materials: The following are available online at http://www.mdpi.com/2077-0383/8/9/1457/s1, Figure S1: Kaplan-Meier curves and adjusted hazard ratios for secondary outcomes, Figure S2: Kaplan-Meier curves for different types of stroke in all patients, Figure S3: Kaplan-Meier curves for different types of stroke in patients with D-dimer levels of $\geq 2.0 \mu \mathrm{g} / \mathrm{mL}$, Figure S4: The cumulative incidence and adjusted hazard ratios according to antithrombotic therapy, Table S1: Baseline clinical and biochemical characteristics in patients included and excluded, Table S2: Baseline characteristics according to antithrombotic therapy, Table S3: Event rates and association estimates from Cox proportional hazard modeling according to antithrombotic therapy, Table S4: Effects of high D-dimer levels on outcomes in patients with paroxysmal and sustained atrial fibrillation, Table S5: Hazard ratios for anticoagulant therapy in patients with the paroxysmal and sustained atrial fibrillation who presented high $(\geq 2 \mu \mathrm{g} / \mathrm{mL})$ baseline D-dimer levels.

Author Contributions: Conceptualization, K.-H.C.; Formal Analysis, K.-H.C. and W.-K.S.; Investigation, K.-H.C. and M.-S.P.; Resources, K.-H.C., W.-K.S., J.-T.K., J.-W.C., O.Y.B., G.-M.K., T.-J.S., B.J.K., S.H.H., J.-M.J., K.O., C.K.K., S.Y., K.Y.P., J.-M.K., J.-H.P., J.C.C., Y.-H.H., and Y.-J.K.; Writing-Original Draft, K.-H.C.; Writing-Review and Editing, K.-H.C., W.-K.S., M.-S.P., O.Y.B., T.-J.S., B.J.K., S.H.H., J.-M.J., K.O., J.-H.P., and Y.-H.H.; Supervision, K.-H.C., W.-K.S., M.-S.P., O.Y.B., and J.-H.P.

Funding: This work was supported by a National Research Foundation of Korea grant funded by the Korean Government (NRF-2019M3A9E8020261, K.-H.C.) and by a grant from the Korean Neurological Association (KNA-17-MI-10, W.-K.S.).

Acknowledgments: We thank Ji-Sung Lee (Clinical Research Center, Department of Biostatistics, ASAN Medical Center, Seoul, Korea) for her help with the statistical analysis.

Conflicts of Interest: W.-K.S. received honoraria for lectures from Pfizer, Sanofi-Aventis, Otsuka Korea, Dong-A Pharmaceutical Co., Ltd., Bayer, Daewoong Pharmaceutical Co., Ltd., Daiichi Sankyo Korea Co., Ltd., and Boryung pharmaceutical; study grants from Daiichi Sankyo Korea Co., Ltd. and National Research Foundation of Republic of Korea (NRF-2017R1A2B4010648); and a consulting fee from OBELAB Inc. J.-M.J. has received lecture honoraria from Pfizer, Sanofi-Aventis, Dong-A Pharmaceutical Co., Ltd., and Boryung Pharmaceutical Co., Ltd.; a study grants from Il-dong, Cheiljedang Pharmaceutical Co., Ltd. and National Research Foundation of Korea (NRF) funded by the Ministry of Science and ICT (NRF-2017R1C1B1009482); and consulting fees from OBELAB Inc. The other authors report no conflicts of interest.

\section{References}

1. Hankey, G.J. Stroke. Lancet 2017, 389, 641-654. [CrossRef]

2. Spence, J.D. Secondary stroke prevention. Nat. Rev. Neurol. 2010, 6, 477-486. [CrossRef] [PubMed]

3. Powers, W.J.; Rabinstein, A.A.; Ackerson, T.; Adeoye, O.M.; Bambakidis, N.C.; Becker, K.; Biller, J.; Brown, M.; Demaerschalk, B.M.; Hoh, B.; et al. 2018 Guidelines for the Early Management of Patients with Acute Ischemic Stroke: A Guideline for Healthcare Professionals from the American Heart Association/American Stroke Association. Stroke 2018, 49, e46-e110. [CrossRef] [PubMed]

4. Goto, S.; Bhatt, D.L.; Rother, J.; Alberts, M.; Hill, M.D.; Ikeda, Y.; Uchiyama, S.; D'Agostino, R.; Ohman, E.M.; Liau, C.S.; et al. Prevalence, clinical profile, and cardiovascular outcomes of atrial fibrillation patients with atherothrombosis. Am. Heart J. 2008, 156, 855-863. [CrossRef] [PubMed]

5. Hijazi, Z.; Oldgren, J.; Siegbahn, A.; Granger, C.B.; Wallentin, L. Biomarkers in atrial fibrillation: A clinical review. Eur. Heart J. 2013, 34, 1475-1480. [CrossRef]

6. Christersson, C.; Wallentin, L.; Andersson, U.; Alexander, J.H.; Ansell, J.; De Caterina, R.; Gersh, B.J.; Granger, C.B.; Hanna, M.; Horowitz, J.D.; et al. D-dimer and risk of thromboembolic and bleeding events in patients with atrial fibrillation-Observations from the ARISTOTLE trial. J. Thromb. Haemost. 2014, 12, 1401-1412. [CrossRef] [PubMed] 
7. Siegbahn, A.; Oldgren, J.; Andersson, U.; Ezekowitz, M.D.; Reilly, P.A.; Connolly, S.J.; Yusuf, S.; Wallentin, L.; Eikelboom, J.W. D-dimer and factor VIIa in atrial fibrillation-Prognostic values for cardiovascular events and effects of anticoagulation therapy. A RE-LY substudy. Thromb. Haemost. 2016, 115, 921-930. [CrossRef]

8. Christersson, C.; Wallentin, L.; Andersson, U.; Alexander, J.H.; Alings, M.; De Caterina, R.; Gersh, B.J.; Granger, C.B.; Halvorsen, S.; Hanna, M.; et al. Effect of apixaban compared with warfarin on coagulation markers in atrial fibrillation. Heart 2019, 105, 235-242. [CrossRef]

9. Kelly, M.S.; Moczygemba, L.R.; Gatewood, S.S. Concordance of Pharmacist Assessment of Medication Nonadherence with a Self-Report Medication Adherence Scale. J. Pharm. Pract. 2016, 29, 194-198. [CrossRef]

10. Nagueh, S.F.; Smiseth, O.A.; Appleton, C.P.; Byrd, B.F., 3rd; Dokainish, H.; Edvardsen, T.; Flachskampf, F.A.; Gillebert, T.C.; Klein, A.L.; Lancellotti, P.; et al. Recommendations for the Evaluation of Left Ventricular Diastolic Function by Echocardiography: An Update from the American Society of Echocardiography and the European Association of Cardiovascular Imaging. Eur. Heart J. Cardiovasc. Imaging 2016, 17, 1321-1360. [CrossRef]

11. Connolly, S.J.; Ezekowitz, M.D.; Yusuf, S.; Eikelboom, J.; Oldgren, J.; Parekh, A.; Pogue, J.; Reilly, P.A.; Themeles, E.; Varrone, J.; et al. Dabigatran versus warfarin in patients with atrial fibrillation. N. Engl. J. Med. 2009, 361, 1139-1151. [CrossRef] [PubMed]

12. Miller, J.D.; Aronis, K.N.; Chrispin, J.; Patil, K.D.; Marine, J.E.; Martin, S.S.; Blaha, M.J.; Blumenthal, R.S.; Calkins, H. Obesity, Exercise, Obstructive Sleep Apnea, and Modifiable Atherosclerotic Cardiovascular Disease Risk Factors in Atrial Fibrillation. J. Am. Coll. Cardiol. 2015, 66, 2899-2906. [CrossRef] [PubMed]

13. Koracevic, G.P. Pragmatic classification of the causes of high D-dimer. Am. J. Emerg. Med. 2009, 27, $1016-\mathrm{e} 5$. [CrossRef] [PubMed]

14. Habara, S.; Dote, K.; Kato, M.; Sasaki, S.; Goto, K.; Takemoto, H.; Hasegawa, D.; Matsuda, O. Prediction of left atrial appendage thrombi in non-valvular atrial fibrillation. Eur. Heart J. 2007, 28, 2217-2222. [CrossRef] [PubMed]

15. Krarup, L.H.; Sandset, E.C.; Sandset, P.M.; Berge, E. D-dimer levels and stroke progression in patients with acute ischemic stroke and atrial fibrillation. Acta Neurol. Scand. 2011, 124, 40-44. [CrossRef] [PubMed]

16. Hijazi, Z.; Lindback, J.; Alexander, J.H.; Hanna, M.; Held, C.; Hylek, E.M.; Lopes, R.D.; Oldgren, J.; Siegbahn, A.; Stewart, R.A.; et al. The ABC (age, biomarkers, clinical history) stroke risk score: A biomarker-based risk score for predicting stroke in atrial fibrillation. Eur. Heart J. 2016, 37, 1582-1590. [CrossRef]

17. Ruff, C.T.; Giugliano, R.P.; Braunwald, E.; Murphy, S.A.; Brown, K.; Jarolim, P.; Mercuri, M.; Antman, E.M.; Morrow, D.A. Cardiovascular Biomarker Score and Clinical Outcomes in Patients with Atrial Fibrillation: A Subanalysis of the ENGAGE AF-TIMI 48 Randomized Clinical Trial. JAMA Cardiol 2016, 1, 999-1006. [CrossRef]

18. Choi, J.Y.; Jung, J.M.; Kwon, D.Y.; Park, M.H.; Kim, J.H.; Oh, K.; Koh, S.B.; Seo, W.K. Free fatty acid as an outcome predictor of atrial fibrillation-associated stroke. Ann. Neurol. 2016, 79, 317-325. [CrossRef]

19. Feinberg, W.M.; Erickson, L.P.; Bruck, D.; Kittelson, J. Hemostatic markers in acute ischemic stroke. Association with stroke type, severity, and outcome. Stroke 1996, 27, 1296-1300. [CrossRef]

20. Montaner, J.; Perea-Gainza, M.; Delgado, P.; Ribo, M.; Chacon, P.; Rosell, A.; Quintana, M.; Palacios, M.E.; Molina, C.A.; Alvarez-Sabin, J. Etiologic diagnosis of ischemic stroke subtypes with plasma biomarkers. Stroke 2008, 39, 2280-2287. [CrossRef]

21. Paciaroni, M.; Agnelli, G.; Falocci, N.; Caso, V.; Becattini, C.; Marcheselli, S.; Rueckert, C.; Pezzini, A.; Poli, L.; Padovani, A.; et al. Early Recurrence and Cerebral Bleeding in Patients with Acute Ischemic Stroke and Atrial Fibrillation: Effect of Anticoagulation and Its Timing: The RAF Study. Stroke 2015, 46, 2175-2182. [CrossRef] [PubMed]

22. Koga, M.; Yoshimura, S.; Hasegawa, Y.; Shibuya, S.; Ito, Y.; Matsuoka, H.; Takamatsu, K.; Nishiyama, K.; Todo, K.; Kimura, K.; et al. Higher Risk of Ischemic Events in Secondary Prevention for Patients with Persistent Than Those with Paroxysmal Atrial Fibrillation. Stroke 2016, 47, 2582-2588. [CrossRef] [PubMed]

23. Takabayashi, K.; Hamatani, Y.; Yamashita, Y.; Takagi, D.; Unoki, T.; Ishii, M.; Iguchi, M.; Masunaga, N.; Ogawa, H.; Esato, M.; et al. Incidence of Stroke or Systemic Embolism in Paroxysmal Versus Sustained Atrial Fibrillation: The Fushimi Atrial Fibrillation Registry. Stroke 2015, 46, 3354-3361. [CrossRef] [PubMed]

24. Al-Saady, N.M.; Obel, O.A.; Camm, A.J. Left atrial appendage: Structure, function, and role in thromboembolism. Heart 1999, 82, 547-554. [CrossRef] [PubMed] 
25. Stoddard, M.F.; Dawkins, P.R.; Prince, C.R.; Ammash, N.M. Left atrial appendage thrombus is not uncommon in patients with acute atrial fibrillation and a recent embolic event: A transesophageal echocardiographic study. J. Am. Coll. Cardiol. 1995, 25, 452-459. [CrossRef]

26. Park, H.C.; Shin, J.; Ban, J.E.; Choi, J.I.; Park, S.W.; Kim, Y.H. Left atrial appendage: Morphology and function in patients with paroxysmal and persistent atrial fibrillation. Int. J. Cardiovasc. Imaging 2013, 29, 935-944. [CrossRef]

27. Manning, W.J.; Weintraub, R.M.; Waksmonski, C.A.; Haering, J.M.; Rooney, P.S.; Maslow, A.D.; Johnson, R.G.; Douglas, P.S. Accuracy of transesophageal echocardiography for identifying left atrial thrombi. A prospective, intraoperative study. Ann. Intern. Med. 1995, 123, 817-822. [CrossRef] [PubMed]

28. Herzog, C.A.; Bass, D.; Kane, M.; Asinger, R. Two-dimensional echocardiographic imaging of left atrial appendage thrombi. J. Am. Coll. Cardiol. 1984, 3, 1340-1344. [CrossRef]

29. Anaissie, J.; Monlezun, D.; Seelochan, A.; Siegler, J.E.; Chavez-Keatts, M.; Tiu, J.; Pineda, D.; George, A.; Shaban, A.; Abi Rafeh, N.; et al. Left Atrial Enlargement on Transthoracic Echocardiography Predicts Left Atrial Thrombus on Transesophageal Echocardiography in Ischemic Stroke Patients. Biomed. Res. Int. 2016, 2016, 7194676. [CrossRef]

30. Paciaroni, M.; Agnelli, G.; Falocci, N.; Caso, V.; Becattini, C.; Marcheselli, S.; Rueckert, C.; Pezzini, A.; Poli, L.; Padovani, A.; et al. Prognostic value of trans-thoracic echocardiography in patients with acute stroke and atrial fibrillation: Findings from the RAF study. J. Neurol. 2016, 263, 231-237. [CrossRef]

31. Seo, W.K.; Jung, J.M.; Kim, J.H.; Koh, S.B.; Bang, O.Y.; Oh, K. Free Fatty Acid Is Associated with Thrombogenicity in Cardioembolic Stroke. Cerebrovasc. Dis. 2017, 44, 160-168. [CrossRef] [PubMed]

32. Wan, H.; Wu, S.; Yang, Y.; Zhu, J.; Zhang, A.; Liang, Y. Plasma fibrin D-dimer and the risk of left atrial thrombus: A systematic review and meta-analysis. PLoS ONE 2017, 12, e0172272. [CrossRef] [PubMed]

33. Pathan, F.; Hecht, H.; Narula, J.; Marwick, T.H. Roles of Transesophageal Echocardiography and Cardiac Computed Tomography for Evaluation of Left Atrial Thrombus and Associated Pathology: A Review and Critical Analysis. JACC Cardiovasc. Imaging 2018, 11, 616-627. [CrossRef] [PubMed]

34. Manning, W.J.; Silverman, D.I.; Waksmonski, C.A.; Oettgen, P.; Douglas, P.S. Prevalence of residual left atrial thrombi among patients with acute thromboembolism and newly recognized atrial fibrillation. Arch. Intern. Med. 1995, 155, 2193-2198. [CrossRef] [PubMed]

35. Jaber, W.A.; Prior, D.L.; Thamilarasan, M.; Grimm, R.A.; Thomas, J.D.; Klein, A.L.; Asher, C.R. Efficacy of anticoagulation in resolving left atrial and left atrial appendage thrombi: A transesophageal echocardiographic study. Am. Heart J. 2000, 140, 150-156. [CrossRef] [PubMed]

36. Toyoda, K.; Ninomiya, T. Stroke and cerebrovascular diseases in patients with chronic kidney disease. Lancet Neurol. 2014, 13, 823-833. [CrossRef]

37. Gordge, M.P.; Faint, R.W.; Rylance, P.B.; Ireland, H.; Lane, D.A.; Neild, G.H. Plasma D dimer: A useful marker of fibrin breakdown in renal failure. Thromb. Haemost. 1989, 61, 522-525. [CrossRef]

38. Heidbuchel, H.; Verhamme, P.; Alings, M.; Antz, M.; Diener, H.C.; Hacke, W.; Oldgren, J.; Sinnaeve, P.; Camm, A.J.; Kirchhof, P.; et al. Updated European Heart Rhythm Association practical guide on the use of non-vitamin-K antagonist anticoagulants in patients with non-valvular atrial fibrillation: Executive summary. Eur. Heart J. 2017, 38, 2137-2149. [CrossRef]

39. Kim, S.J.; Ryoo, S.; Kwon, S.; Park, Y.K.; Kim, J.P.; Lee, G.Y.; Bang, O.Y. Is atrial fibrillation always a culprit of stroke in patients with atrial fibrillation plus stroke? Cerebrovasc. Dis. 2013, 36, 373-382. [CrossRef]

40. Mohr, J.P.; Thompson, J.L.; Lazar, R.M.; Levin, B.; Sacco, R.L.; Furie, K.L.; Kistler, J.P.; Albers, G.W.; Pettigrew, L.C.; Adams, H.P., Jr.; et al. A comparison of warfarin and aspirin for the prevention of recurrent ischemic stroke. N. Engl. J. Med. 2001, 345, 1444-1451. [CrossRef]

41. McGrath, E.R.; Kapral, M.K.; Fang, J.; Eikelboom, J.W.; Conghaile, A.; Canavan, M.; O’Donnell, M.J.; Investigators of the Ontario Stroke, R. Antithrombotic therapy after acute ischemic stroke in patients with atrial fibrillation. Stroke 2014, 45, 3637-3642. [CrossRef] [PubMed]

42. Miyazawa, K.; Li, Y.G.; Rashed, W.A.; Al Mahmeed, W.; Shehab, A.; Zubaid, M.; Lip, G.Y.H. Secondary stroke prevention and guideline adherent antithrombotic treatment in patients with atrial fibrillation: Insights from the Gulf Survey of atrial fibrillation events (Gulf SAFE). Int. J. Cardiol. 2019, 274, 126-131. [CrossRef] [PubMed] 
43. Nakatani, Y.; Mizumaki, K.; Nishida, K.; Hirai, T.; Sakabe, M.; Oda, Y.; Joho, S.; Fujiki, A.; Nozawa, T.; Inoue, H. Anticoagulation control quality affects the D-dimer levels of atrial fibrillation patients. Circ. J. 2012, 76, 317-321. [CrossRef] [PubMed]

44. Lee, M.J.; Chung, J.W.; Ahn, M.J.; Kim, S.; Seok, J.M.; Jang, H.M.; Kim, G.M.; Chung, C.S.; Lee, K.H.; Bang, O.Y. Hypercoagulability and Mortality of Patients with Stroke and Active Cancer: The OASIS-CANCER Study. J. Stroke 2017, 19, 77-87. [CrossRef] [PubMed]

45. Severino, P.; Mariani, M.V.; Maraone, A.; Piro, A.; Ceccacci, A.; Tarsitani, L.; Maestrini, V.; Mancone, M.; Lavalle, C.; Pasquini, M.; et al. Triggers for Atrial Fibrillation: The Role of Anxiety. Cardiol. Res. Pract. 2019, 2019, 1208505. [CrossRef] [PubMed]

46. Lau, D.H.; Nattel, S.; Kalman, J.M.; Sanders, P. Modifiable Risk Factors and Atrial Fibrillation. Circulation 2017, 136, 583-596. [CrossRef]

(C) 2019 by the authors. Licensee MDPI, Basel, Switzerland. This article is an open access article distributed under the terms and conditions of the Creative Commons Attribution (CC BY) license (http://creativecommons.org/licenses/by/4.0/). 